Nig. J. Biotech. Vol. 36 (1): 1-8 (June 2019)

ISSN: 01891731

Available online at

http://www.ajol.info/index.php/njb/index

and www.biotechsocietynigeria.org

DOI: https://dx.doi.org/10.4314/njb.v36i1.1

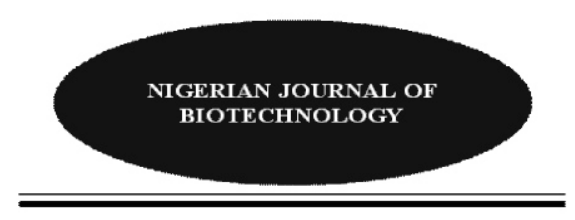

\title{
Reaction of gum arabic samples with monoclonal antibodies directed to plant cell wall polymers in dot immunobinding
}

${ }^{1}$ Samaila, J. T. and ${ }^{2}$ Gashua, I. B.

${ }^{1}$ Department of Agricultural Education

College of Education Hong - Adamawa state, Nigeria.

${ }^{2}$ Department of Science Laboratory Technologies

Federal Polytechnic Damaturu - Yobe state, Nigeria.

\begin{abstract}
Copyright resides with the authors in terms of the Creative Commons License 4.0.
(See http://creativecommons.org/licenses/by/4.0/).

Condition of use: The user may copy, distribute, transmit and adapt the work, but must recognize the authors and the Nigerian Journal of Biotechnology.
\end{abstract}

\section{Abstract}

Certain plant cell wall constituents have been found in gum samples derived from Acacia trees, thus analytical techniques for the determination of these plant cell wall components in any media can be applied in the analysis of the physico-chemical properties of these gums. In this experiment, gum samples harvested from various Acacia trees grown in different African countries were subjected to a dot immunobinding reaction using a panel of anti-plant cell wall directed monoclonal antibodies since the gum samples have been found to contain certain plant cell wall constituents. Five antiplant cell wall monoclonal antibodies, JIM 5, JIM 7, JIM 13, LM 6 and MAC 207 were reacted with fifteen gum Arabic samples 1-15 and water as control. The results showed that apart from reacting with the monoclonal antibodies, gum samples showed varying degrees of reactivity with the monoclonal antibodies. JIM 5 indicated no reaction with any of the gum samples, whereas JIM 7, JIM 13, LM 6 and MAC 207 exhibited reactions with the samples. The results suggest that, anti-plant cell wall directed monoclonal antibodies can be used as a tool to distinguish between gum Arabic samples from different tree species, as well as from different African countries. Thus, a testing kit which is easy to use and cheaper to acquire can be developed using anti-plant cell wall monoclonal antibodies, to improve quality control in the current gum trade.

Corresponding author: jsamaila@harper-adams.ac.uk

\section{Introduction}

A dot immunobinding also known as dot blot is a technique in molecular biology used to detect proteins, in which the sample is applied directly on a membrane at a single spot and the blotting technique is performed. The technique permits assays of multiple specimens simultaneously on single strips of blotting media, thereby offering significant savings in time and resources (Renner, 1988). By international standards gum Arabic is recognised as "a dried exudate obtained from the stems and branches of Acacia senegal (L.) Willdenow, or Acacia seyal (fam. Leguminosae)" (WHO, 2000; FAO, 1999).
Currently, Sudan and Nigeria are the world's first and second largest producers of gum arabic respectively, supplying approximately $80 \%$ of the world's demand. The genus Acacia from which gum arabic is obtained is one of the largest vascular plant genera thriving in a wide range of ecological environments from the arid deserts to tropical climates in Australia, Africa, India and America (Abdel-Gadir et al., 2014). The value of gum Arabic arises from its vast applications in the production of a wide variety of commercial goods in the food, pharmaceutical, cosmetic, lithographic, pottery and textile industries because of its ability to stabilise emulsions, act as 


\section{Samaila and Gashua/ Nig. J. Biotech. Vol. 36 Num. 1: 1-8 (June 2019)}

a thickening agent and its excellent emulsifying properties among others (Ali et al., 2012). However, it is in the food industry that the majority of gum Arabic is utilised (Ali et al., 2009). Since it is a natural substance, gum Arabic exhibits natural variations in its composition, which influences the quality of the final products obtained. The quality of gum Arabic vary with certain conditions including soil type and the location of growth of the parent plant - Acacia (Idris et al., 1998; Idris \& Haddad, 2012). Therefore, there are intrinsic differences in the physico-chemical characteristics depending on species and locations. The most important gum yielding species in terms of their global agronomic importance are, $A$. senegal and $A$. seyal, with $A$. Senegal widely recognised as the more important of the two. As a commodity of international trade, gum Arabic is subjected to rigorous quality regulations, specifications and controls to avoid dealing in adulterated samples. One of the important factors determining the quality, marketability and utilization of a particular gum sample is the physico-chemical characteristics (Chikamai, 1997). Therefore, molecular tools for determining its composition have been of great benefit to the gum trade and end users. To this end a number of tools have been used to identify the molecular compositions of gums from trees grown in different countries with a view to distinguishing between them. Reports have demonstrated the utility of a panel of anti-plant cell wall monoclonal antibodies in combination with chemical/physicochemical analyses in determining molecular compositions of different gum samples (Osman et al., 1993). Menzies et al. (1996) employed a panel of anti- plant cell wall monoclonal antibodies in a serotaxanomic study of Acacia gum exudates from various countries in Africa. The results showed some gum samples harvested from same species showing wide differences in their molecular compositions compared to gum samples from taxonomically unrelated species. Moreover, gums from different sub-species of a single species had very distinct molecular compositions. The above findings create a possibility for the application of a panel of the monoclonal antibodies as a toolkit for carrying out comparisons between the commercial Acacia senegal gum samples from different locations as the need for cheap and effective tools that permit for the recognition of the gums' natural differences continues (Yebeyen et al., 2009). The aim of this paper is to evaluate the reaction of some gum samples with monoclonal antibodies in immuno dot-blots as a step towards optimizing immuno dot-blots as a tool for determining the molecular similarities and differences between gum Arabic samples harvested from different African countries, particularly Nigeria and Sudan.

\section{Materials and methods}

Preparation of gum exudate samples

A total of 15 gum samples derived from Acacia senegal trees, in the form of freeze-dried powders were dissolved in sterile distilled water (SDW) to a concentration of $20 \mathrm{mg} / \mathrm{ml}$ in separate eppendorf tubes and stored in a freezer at $-20^{\circ} \mathrm{C}$.

\section{Monoclonal antibodies used}

Monoclonal antibodies directed to cell wall polymers used in the experiment are listed in Table 1.

Table 1. Monoclonal antibodies and the antigens being detected.

\begin{tabular}{ll}
\hline Monoclonal antibody & \multicolumn{1}{c}{ Antigen detected } \\
\hline JIM 5 & Partially methyl- esterified HG/ no ester (Li et al., 1995) \\
JIM7 & High methyl-esterified homogalacturonan epitope (Clausen, et al., 2003) \\
JIM13 & Arabinogalactan-protein (Yates et al., 1996) \\
Lm6 & 1, 5- $\alpha$-L-Arabinan (Moller et al., 2008; Verhertbruggen et al., 2009; Willats, et al., 1998). \\
MAC 207 & Arabinogalactan-protein (Li et al., 1995; Yates, et al., 1996) \\
\hline
\end{tabular}

Immunobinding/Immuno-dot blots

The immuno-dot blots were performed by preparing a duplicate of two nitrocellulose membrane strips for each antibody used. Membrane strips are prepared by drawing eight $1 \mathrm{~cm}$ long squares on the top of each of them, the upper left corners of each strip were cut to mark the beginning of the strip. Antibody used was labelled on the first square as well. The last squares on each strip were served as a negative control $(1 \mu$ l of sterile distilled water (SDW)). The prepared strips were then placed in small plastic trays and $1 \mu \mathrm{l}(20 \mu \mathrm{g})$ of the gum samples were dotted onto the nitrocellulose membrane and left air-drying for 30 minutes. The membranes were then incubated in $1 \times$ TBS (Tris buffered saline) $\mathrm{pH}$ 7.4 for 5 minutes. Next, the membranes were incubated in a $5 \%$ solution of skimmed milk powder in $10 \mathrm{ml} 1 \mathrm{x}$ TBS which acts as blocking solution for 1 hour. $200 \mu$ l of primary antibody 


\section{Samaila and Gashua/ Nig. J. Biotech. Vol. 36 Num. 1: 1-8 (June 2019)}

was added to the blocking solution (1:50 dilution) and incubated for 2 hours. The membranes were then washed 4 times for 5 minutes with $1 x$ TBS. $10 \mu$ l of secondary antibody was then added together with the $10 \mathrm{ml}$ of blocking solution to the dot-blots and incubated for 1 hour after the removal of $1 x$ TBS. The membranes were again washed 6 times for 5 minutes with $1 \mathrm{x}$ TBS. $10 \mathrm{ml}$ of alkaline phosphatase buffer containing $66 \mu$ l of nitro blue tetrazolium (NBT) and $33 \mu \mathrm{l}$ of 5-bromo-4chloro-indolyl-phosphate (BCIP) was added to detect the existence of the bound antibodies. When the blots were fully developed on the nitrocellulose membranes (15 minutes), the detection buffer was removed. The membranes were then rinsed with SDW, air-dried and photographed.

\section{Results}

Reactions with JIM 5

JIM5 is a monoclonal antibody which readily reacts with partially methyl-esterified pectin epitope. In this experiment, JIM5 could not bind to gum samples from Acacia seyal from Sudan (sample 14), Acacia compylacantha from Zimbabwe (sample 9), Acacia karroo from the Sudan (sample 10) and Acacia verek from Nigeria (sample 12). However, it had a strong reaction with the sample from Acacia nilotica from Sudan (sample 8) (Fig.1).

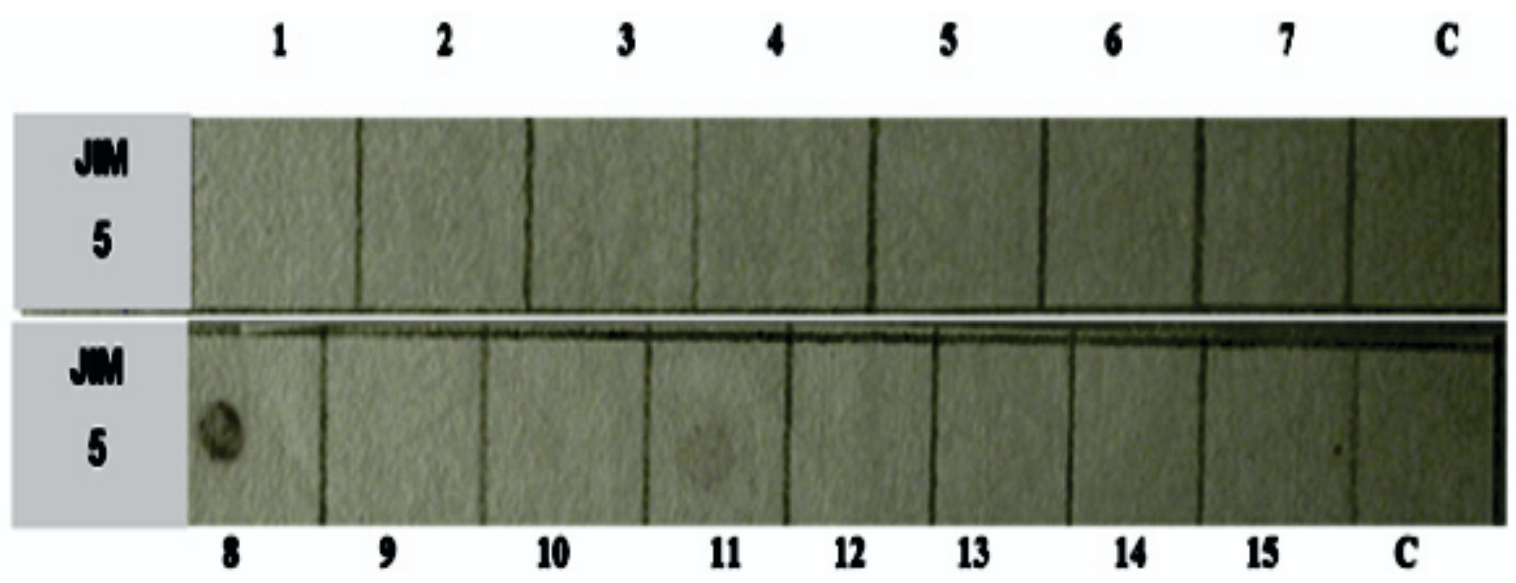

Fig.1. Immuno dot-blot results for samples probed with monoclonal antibody JIM5. Where, $1-15$ are samples $1-15$ and C is negative control. JIM5 reacted with only sample 8, all other samples $1-7$ and 9 -15 did not show evidence of reaction with JIM 5.

\section{Reactions with JIM 7}

For JIM7 that reacts with a highly methylesterified HG epitope, strong reactions were demonstrated with the gum samples harvested from Acacia senegal sample (4) in Sudan and moderate interactions with other gum Samples 2, 6, 5 and 15 from Acacia senegal from Sudan, Chad and Nigeria. Weak reactions were however shown with Acacia senegal samples 7 and 15 from Ethiopia and Nigeria respectively and no reactions with Samples 1 and 13 from Sudan and Nigeria. Gum samples from Acacia sayel and Acacia nilotica both of Sudanese origin demonstrated moderate reactions with JIM7, while gum samples from Acacia compylacacantha showed no reaction with the antibody (Fig. 2).

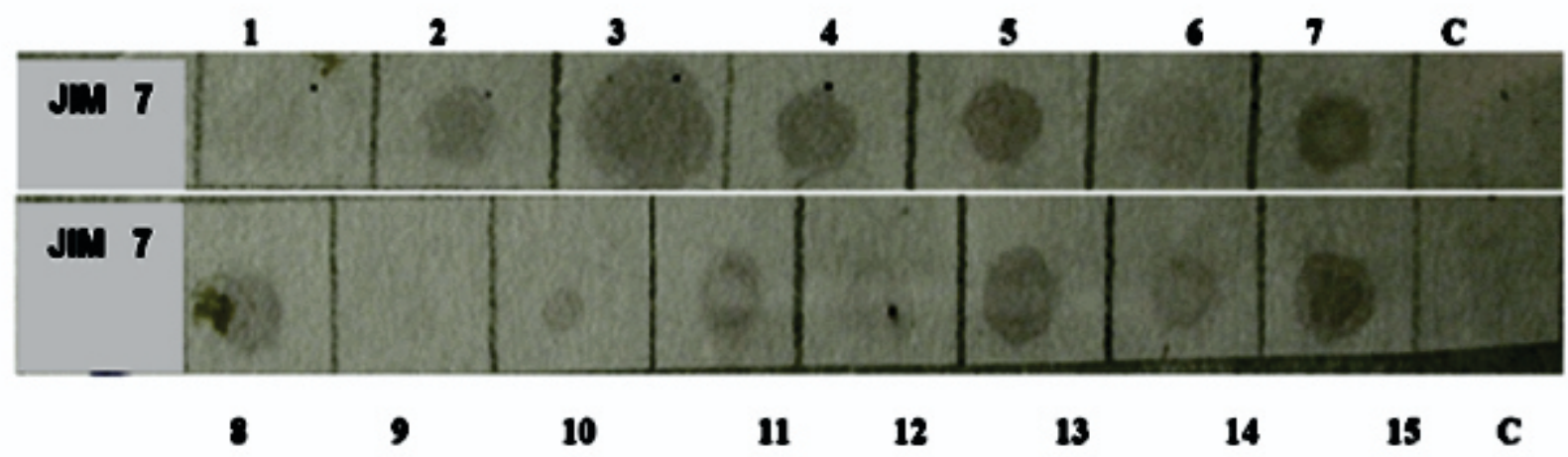

Fig. 2. Immuno dot-blot results for samples probed with monoclonal antibody JIM7. Where, $1-15$ shows samples 1 - 15 and C, is negative control. JIM 7 showed reactions with samples $1-8$ and samples $11-15$. No reaction was observed with samples 9 and 10. 
Reactions with JIM 13

JIM13 raised against arabinogalactanprotein (AGP) had no reaction at all with gum samples from Nigeria. LM6, another antipectin antibody, recognising pectin rhamnogalacturonan- 1 (RG-1) $(1 \rightarrow 5$, L arabinan) (Willats, et al., 1998) showed very strong reactions with all the gum samples from Sudan and Nigeria, indicating the possibility of a large amount of this type of pectin rhamnogalacturonan-1 in all the samples (Fig. 3).

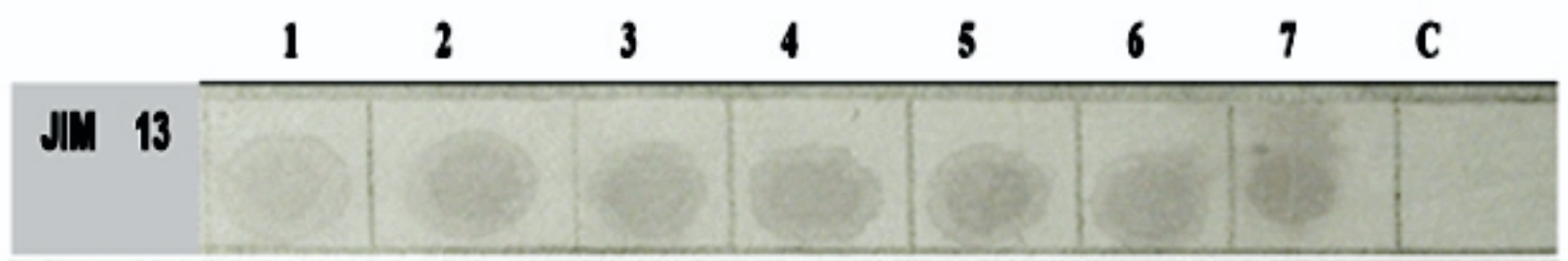

\section{JIII 13}

\section{$8 \quad 9 \quad 10 \quad 1$}

$12 \quad 13$

$14 \quad 15$

C

Fig. 3. Immuno dot-blot results for samples probed with monoclonal antibody JIM13. Where $1-15$ represents samples $1-15$ and $C$, is negative control. The monoclonal antibody JIM13 showed reaction with samples 1-14, and no reaction with samples 15.

\section{Reactions with LM 6}

Lm6, another antipectin antibody, recognising pectin rhamnogalacturonan- 1 (RG1) $(1 \rightarrow 5$, L - arabinan) (Willats et al., 1998) showed very strong reactions with all the gum samples from Sudan and Nigeria, indicating the possibility of a large amount of this type of pectin rhamnogalacturonan-1 in all the samples (Fig.4).

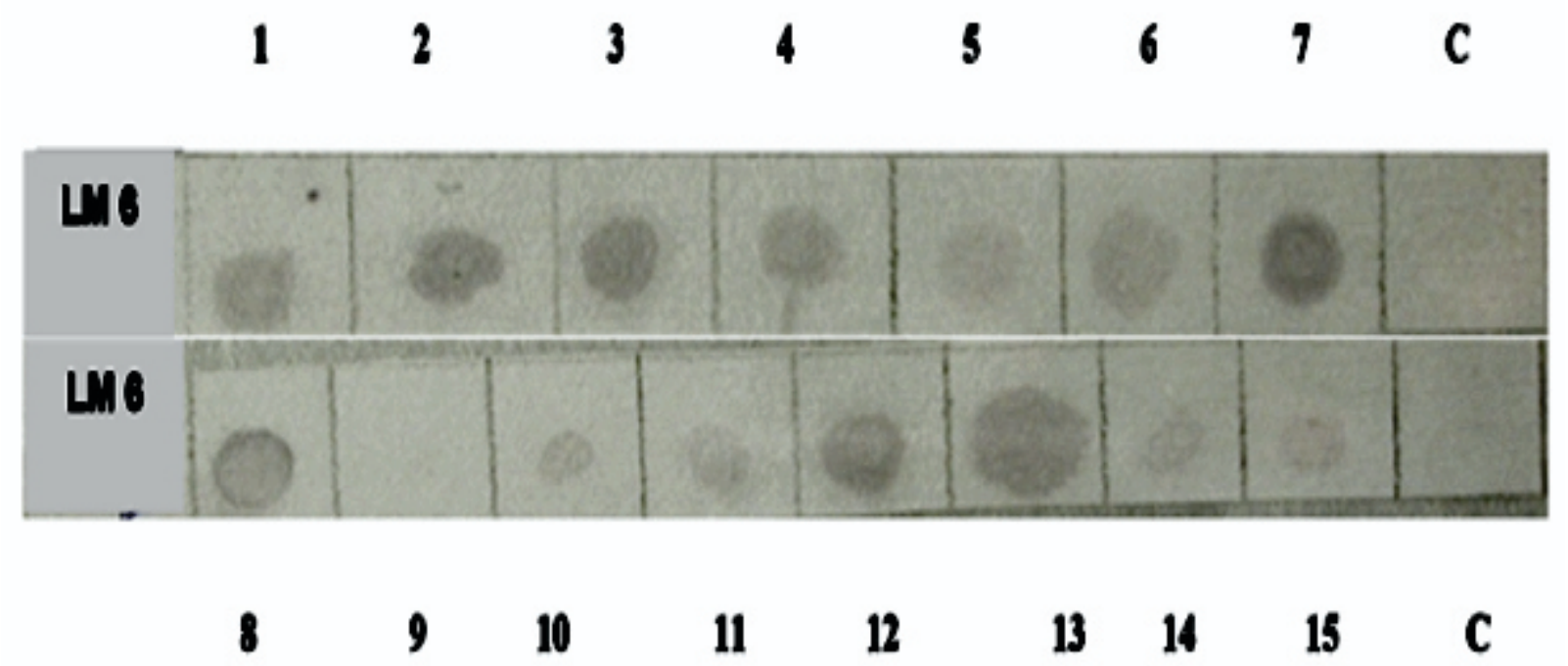

Fig. 4. Immuno dot-blot results for samples probed with monoclonal antibody LM6. Where, $1-15$ represents samples $1-15$ and C, is negative control. Reactions between the monoclonal antibody LM6, and sample $1-8$ and samples 10 - 15 were observed, while no reactions were observed with sample 9 .

Reactions with MAC 207.

MAC207 which recognizes arabinogalactan-protein (AGP) (Moller et al., 2008) shows a moderate reaction with Acacia senegal gums from Sudan and a strong reaction with those from Nigeria, which indicates that there may be higher levels of AGP's in the gum samples from Nigeria than those from Sudan (Fig. 5). 
Samaila and Gashua/ Nig. J. Biotech. Vol. 36 Num. 1: 1-8 (June 2019)
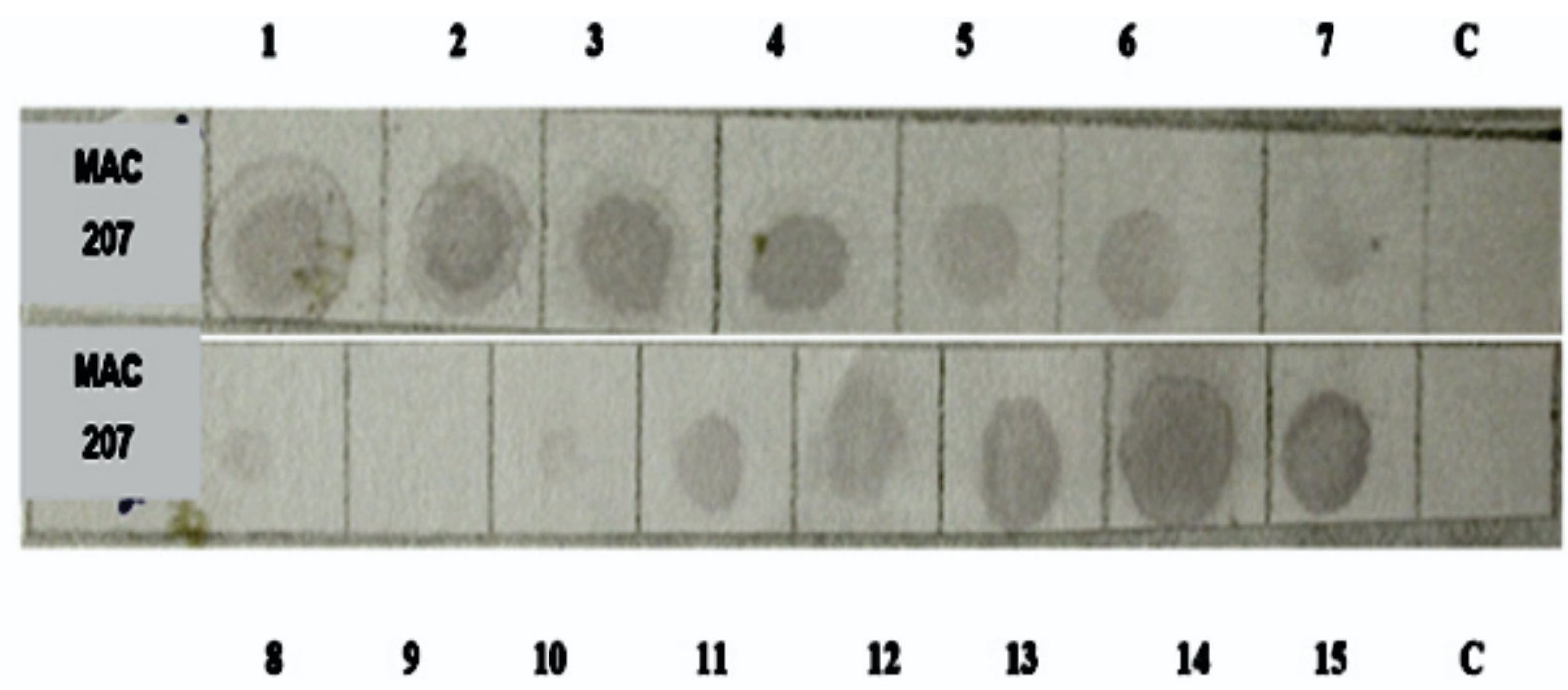

Fig. 5. Immuno dot-blot results for samples probed with monoclonal antibody MAC207. Where, $1-15$ stands for samples $1-15$ and $C$ is negative control. Samples 1- 6, 11-15 showed reactions with the MAC 207, while 8-10 did not show any reaction.

\section{Discussion}

Identification of different plant cell wall epitopes using monoclonal antibodies

There is ample evidence for the presence of a number of plant cell wall epitopes being detected by the monoclonal antibodies in most of the gum Arabic samples originating from both Nigeria and Sudan. JIM 5 monoclonal antibody did not show reaction with most samples under investigation, but reacted strongly with sample 8 . This result shows the presence of the partially esterified region in the HG molecule in sample 8 from the Acacia nilotica from Sudan and its absence from all other samples. Menzies et al. (1992) obtained a similar result showing JIM 5 bound differently to gums depending on their botanical series. It reacted strongly with gums from Gummiferae series and not at all with those from the Vulgares series. The antibody appears rather more specific to gums from trees in the Gummiferae series. Christiaens et al., (2011) found that the binding ability of JIM 5 to pectin apparently increases with decreasing degree of esterification. Therefore, further tests to detect methyl esterification status of the gum samples and their botanical series may be required to draw conclusions about gum reactions with JIM 5.

Reactions with JIM 7 indicate there could be absence of highly methyl-esterified pectins hence no reactions when probed with JIM 7 in the Acacia senegal gum samples from Sudan (sample 1) and Nigeria (sample 13) and Acacia compylacantha (sample 9) from Zimbabwe and that of Acacia karro (sample 10) from Zimbabwe. A similar trend of reaction has been reported (Baldwin et al., 1999) which indicated the absence of the highly methyl esterified pectins in gum samples harvested from Acacia senegal, Acacia compylantha and Acacia karro.

Regarding JIM 5 and JIM 7, there is apparently high level of sensitivity and specificities of the antibodies in detecting the presence or absence of highly methyl-esterified or partially esterified HG epitopes in plant samples according to methyl esterification (Verhertbruggen et al., 2009). Hence, the differences observed in the reactions of the two antibodies JIM 5 and JIM 7 both of which are anti-pectin. According to Verhertbruggen et al., (2009) HG-directed monoclonal antibodies including JIM 5 and JIM 7 have differing specificities in relation to $\mathrm{HG}$ methylesterification. Thus, for easy delineation of samples using these monoclonal antibodies there is need to consider the methyl esterification status of HG in the gum samples.

On the hand results of reactions with JIM 13 shows that gum samples from Sudan appear to contain arabinogalactan protein epitopes, while those from Nigeria may not. However, MAC 207 which also reacts with arabinogalactan proteins did show reactions with gum samples from Nigeria and Sudan indicating the presence of this protein in the gum samples. The differences in reactions could be due the efficacy of the monoclonal antibodies in detecting the presence of arabinogalactan proteins in the samples. Thus, although both monoclonal antibodies could detect arabinogalactan protein, in this particular instance, JIM 13 had failed to do so, while MAC 207 showed reactions with it. It 
Samaila and Gashua/ Nig. J. Biotech. Vol. 36 Num. 1: 1-8 (June 2019)

can therefore be inferred that MAC 207 is a more robust tool to detect the arabinogalactan proteins in gum Arabic grown in Nigeria and Sudan.

Similarities and differences detected using monoclonal antibodies

The gum sample harvested from Acacia nilotica (sample 8) harvested in Sudan does not share compatibility with gum samples 1, 2, 3, 4 and 6 harvested from Acacia senegal from the Sudan. In addition, the sample harvested from Acacia nilotica (sample 8) from Sudan does not share reaction similarity with gum samples harvested from Acacia senegal from Chad (sample 5), Ethiopia (sample 7) and Nigeria (samples 13, 14 and 15). It did not also have reaction similarities with gum samples harvested from Acacia seyal (sample 14) from Sudan, Acacia compylacantha (sample 9) from Zimbabwe, Acacia karroo (sample 10) from Zimbabwe and Acacia verek (sample 12) from Nigeria. From the reactions between the gum samples and JIM7, it can be deduced that gum samples harvested from Acacia senegal (samples 2 and 6) from Sudan have similarity with those grown in Chad (sample 5) and Nigeria (sample 16). In addition, similarity is shown to exist between gum samples harvested from Acacia seyal (sample 14) and Acacia nilotica (sample 8) both from Sudan. Gum samples harvested from Acacia senegal (samples 2 and 6 ) of Sudanese origin have similarity with those from Chad (sample 5) and those from Nigeria (sample 16) and with samples harvested from Acacia seyal (sample 14) and Acacia nilotica (sample 8) both from in Sudan. Therefore, gums from different species, such as Acacia senegal, Acacia seyal and Acacia nilotica and Acacia compylacantha may exhibit certain characteristics that are different. Moreover, even within the same species e.g. in Acacia senegal, individual trees of different genotypes grown in countries could produce gums with slightly different characteristics due to differences in the agro-ecologies of their countries of origin. Hence, samples harvested from Acacia senegal, sample 1 is the only Acacia senegal sample of Sudanese origin which did not react with JIM7. Both samples (samples 9 and 10) of Zimbabwean origin did not bind to JIM7 though harvested from different species.

The reactions between JIM13 and the gum samples from different Acacia species resulted into certain similarities. Samples harvested from Acacia senegal species 2, 3 and 4 from Sudan and samples harvested from Acacia senegal (sample 7) from Ethiopia shared similarity with the gum exudate samples from Acacia compylacantha (sample 9) from Zimbabwe and Acacia nilotica (sample 8) grown in Sudan. This result agrees with Yebeyen et al. (2009), who found similarity between gum samples harvested from Acacia senegal grown in the rift valley of Ethiopia and gums harvested from Acacia senegal of Sudanese origin.

Similarities were shown to exist between samples 13, 14 and 15 harvested from Acacia senegal species from Nigeria. Gum exudates harvested from Acacia senegal samples (samples 1 and 6) from Sudan may be different from (samples 2, 3 and 4) from Acacia senegal of Sudanese origin. These samples harvested from Acacia senegal of Sudanese origin also showed similarities with gum sample harvested from Acacia seyal (sample14) from Sudan because it also did not react with JIM13. However, they may be similar to gum samples from Acacia senegal from Chad (sample 5) and gums harvested from Acacia karroo grown in Zimbabwe (sample 10) and Acacia verek from Nigeria (sample 12). Thus, despite the diversities of the Acacia species in terms of variety and country of origin, there are still some similarities among gum samples harvested. Studies by Habeballa et al. (2010) do not agree with the above similarities among gum samples from Acacia, which concluded that a high level of population differentiation that was geographically structured is common in domesticated Acacia species worldwide.

The reactions of LM6 with the gum samples presented some molecular similarities as follows: among the samples harvested from Acacia Senegal, gum samples (samples 2, 3, 4 and 6) from Sudan share similarities with the gum sample (sample 7) from Ethiopia and the gum sample (sample 13) from Nigeria. In addition, sample harvested from Acacia senegal (sample 1) from Sudan is similar to the sample from Acacia senegal (sample 5) from Chad. Sample from Acacia seyal (sample 14) from Sudan was similar in characteristic to the sample from Acacia nilotica (sample 8) from Sudan. Whereas samples harvested from Acacia senegal (samples 15 and 16) grown in Nigeria shared some similarities with samples from Acacia compylacantha (sample 9) and Acacia karroo (sample 10) both grown in Zimbabwe and with the gum sample (sample 12) harvested from Acacia verek grown in Nigeria. Hence, Acacia senegal samples (sample 6) from Sudan may be similar to samples harvested from Acacia senegal (sample 7) from Ethiopia. Also likely similar are the following: gum samples harvested from Acacia seyal (sample 14) grown in Sudan, Acacia compylacantha (sample 9), Acacia karroo 


\section{Samaila and Gashua/ Nig. J. Biotech. Vol. 36 Num. 1: 1-8 (June 2019)}

(sample 10) of Zimbabwean origin, Acacia nilotica (sample 8) from Sudan and Acacia verek (sample 12) from Nigeria. These are different from, gum samples harvested from Acacia senegal (sample 6) of Sudanese origin and sample harvested from Acacia senegal (sample 7) grown in Ethiopia.

\section{Conclusions}

The results showed that the Acacia senegal gum exudates under study exhibited different levels of reactions with the monoclonal antibodies used. These reactions indicate that the monoclonal antibodies were being bound with specific plant cell wall epitopes in the gum samples. This confirms the presence of certain plant cell wall components in some of the gum samples and not in others, hence the effectiveness of the immune-dot blot technique using anti-plant cell wall monoclonal antibodies in probing the compositions of the gums. With regards to the presence of plant cell wall components in the gum samples, it has been shown that the partially methyl-esterified pectin epitope was completely absent from these gum samples, whereas there was abundance of highly methyl esterified pectin, arabinogalactan carbohydrate moiety (AGP's) and extension in the gum samples from Nigeria and Sudan. However, JIM13, did not show strong reactions with any of the gum samples although it was raised against the AGP glycan, whose presence has been shown in the samples using other monoclonal antibodies. This reaction pattern may be attributed to the complex structure of the AGPs or the weakness of JIM13 to recognise the AGP. Similar incongruent reactions with AGP bearing structures have been expressed and attributed to the complex AGP molecular structure in (Tan et al., 2012). Thus, reactions with JIM13 would require further investigations to draw plausible conclusions. Therefore, the effectiveness of monoclonal antibodies as tools to differentiate between acacia senegal gums from Nigeria and Sudan, has been shown in this experiment. And designing a tool kit for the purpose of ascertaining similarities and differences between these gum samples using this panel of monoclonal antibodies would meet the need for a cheaper, efficient, less laborious and more robust method.

\section{References}

Abdel-Gadir, M. (2014). Sudan exported 42 tonnes of gum Arabic to US in 2013: Sudan Tribune. 7 April, 1.

Ali, B. H., Zaida, A and Blunden, G. (2009).
Biological effects of gum Arabic: A review of some recent research. Food Chem. Toxicol. 47: 1-8.

Ali, N. E. S., Awad, E, F., Fageer, A. S. M. and Nour, A. A. M. (2012). Physiochemical characteristics of some Acacia gums. Int. J agric. res. 7 (8):406 413.

Baldwin T. C., Quah P. E. and Menzies A. R. (1999). A Serotaxonomic study of Acacia gum exudates. Phytochemistry 50 (4):599-606.

Chikamai, B. N. (1997). Production, markets and quality control of gum arabic in Africa: Findings and recommendations from an FAO project. In: J. O. Mugah, B. N. Chikamai, S. S. Mbiru and E. Casade (Eds), conservation management and utilization of plant gums, resins and essential oils. Proceedings of a regional conference for Africa, 6 -10 October 1997, Nairobi, Kenya.

Clausen, M. H., Willats G. T. and Knox J. P. (2003). Synthetic methyl hexagalacturonate hapten inhibitors of anti-homogalacturonan monoclonal antibodies LM7, JIM5 and JIM7. Carbohydr. Res. 338 (17):1797-1800.

Christiaens, S., Sandy, V. B., Euggene, D. N., Evelien, V., Ilse, F., Thomas, D., Ann, M. V. L. and Marc, E. H. (2011) Anti - homogalacturonan antibodies: A way to explore the effect of processing on pectin in fruits and vegetables? Food Res. Int. 44:225-234.

Ellis M., Egelund, J., Schultz C. J. and Bacic, A. (2010). Arabinogalactan-proteins: key regulators at the cell surface? Plant physiol. 153 (2): 403 419.

FAO, (1999). Gum Arabic, gum Talha and other Acacia gums. [Online] (Accessed 10th March, $\left.\begin{array}{llll}2 & 0 & 1 & 6\end{array}\right) \quad A \vee a$ i I a b I e a t : $<$ http://www.fao.org/docrep/x9236e/x9236e05 .htm>.

Habeballa, R. S., Hamza, N. B. and El Gaali, E. I. (2010) Genetic variability in Sudanese Acacia senegal (L.) assessed by random amplified polymorphic DNA. Afr. J. Biotechnol. 9 (30) 4655 -4660 .

Idris, O. H. M., Williams, P. A. and Phillips, G. O. (1998) Characterisation of gum from Acacia senegal trees of different age and location using gel permeation chromatography. Food Hydrocoll. $12(4): 379-388$. 
Idris, O. H. M. and Haddad, G. M. (2012) Gum Arabic's (Gum Acacia's) journey from tree to end user. In Kennedy, J.F., Phillips G.O. and Williams, P.A. (eds.), Gum Arabic. Special ed. Cambridge: 2012 RSC Publishing, UK. 3-19.

Knox, J. P., Linstead, P. J., King, J., Cooper, C. and Roberts, K. (1990). Pectin esterification is spatially regulated both within cell walls and between developing tissues of root apices. Planta, 181(4):512-521.

Li, Y., Faleri, C., Geitmann, A., Zhang, H. and Cresti, M. (1995). Immunogold localization of arabinogalactan proteins, unesterified and esterified pectins in pollen grains and pollen tubes of Nicotiana tabacum L. Protoplasma, 189 $(1-2): 26-36$.

Menzies, A. R., Osman, M. E., Philips, G. O. and Williams, P. A. (1992). An enzyme linked immunosorbent assay (ELISA) for Acacia senegal gum exudate (gum arabic). In: Gums and Stabilizers for the Food Industry. 1992; 6: 507 512.

Osman, M. E., Williams, P. A., A. R. Menzies, A. R. and Philips, G. O. (1993). Characterisation of commercial samples of gum Arabic. J Agric. Food Chem. 41: 71-77.

Renner, S. W. 1988. Immunoblotting and dot immunobinding. Emerging techniques in protein immunochemistry. Arch. Pathol. Lab. Med. 112 (8):780-786.
Tan, L., Showalter, A. M., Egelund, J., HernandezSanchez, A., Doblin, M. S. and Bacic, A. (2012). Arabinogalactan-proteins and the research challenges for these enigmatic plant cell surface proteoglycans. Front. Plant Sci. 3. 140.

Verhertbruggen, Y., Susan E. M., Ash, H., Rene, V., Henk, A. S., Barny, V. M., Lauren, M., Harry, J.G. and J. Paul Knox (2009). Developmental complexity of arabinan polysaccharides and their processing in plant cell walls. Plant J. 59 (3): 413 -425 .

WHO (2000). Evaluation of certain food additives. Fifty-first report of the joint FAO/WHO Expert Committee on food additives. World Health Organisation Technical Report Series, 891: i - viii, 1-168.

Willats, W. G. T., Susan E. M. and Knox J. P. (1998). Generation of a monoclonal antibody specific to $(1 \rightarrow 5)$-a-L-arabinan. Carbohydr. Res. 308 (1):149-152.

Yates, E. A., Valdor, J., Haslam, S. M., Morris, H. R., Dell, A., Mackie, W. and Knox, J. P. (1996) Characterization of carbohydrate structural features recognized by anti-arabinogalactanprotein monoclonal antibodies. Glycobiology, 6 (2):131-139.

Yebeyen, D., Lemenih, M. and Feleke, S. (2009). Characteristics and quality of gum arabic from naturally grown Acacia senegal (Linne) Willd. Trees in the Central Rift Valley of Ethiopia. Food Hydrocoll. 23(1):175-180. 